\title{
Gold Electrodes Modified with Self-Assembled Layers Made of Sulphur Compounds and Gold Nanoparticles Used for Selective Electrocatalytic Oxidation of Catecholamine in the Presence of Interfering Ascorbic and Uric Acids
}

\author{
Teresa Luczak \\ Faculty of Chemistry, A. Mickiewicz University, Grunwaldzka 6, 60-780 Poznań, Poland \\ Correspondence should be addressed to Teresa Łuczak, telucz@amu.edu.pl
}

Received 20 April 2011; Accepted 8 June 2011

Academic Editor: Aleksandar Radu

Copyright (C) 2011 Teresa Łuczak. This is an open access article distributed under the Creative Commons Attribution License, which permits unrestricted use, distribution, and reproduction in any medium, provided the original work is properly cited.

\begin{abstract}
Gold electrodes modified with S-containing compounds and gold nanoparticles were used for determination of epinephrine (EP) in aqueous solution. The modified electrodes exhibited a good sensitivity, reproducibility, and stability. The results have shown that modified electrodes could clearly resolve the oxidation peaks of epinephrine, ascorbic acid (AA), and uric acid (UA) with peak-to-peak separation enabling determination of EP, AA, and UA in their simultaneous presence. A linear relationship between $\mathrm{EP}$ concentration and current response was obtained in the range of $0.1 \mu \mathrm{M}$ to $700 \mu \mathrm{M}$ with the detection limit $\geq 0.034 \mu \mathrm{M}$ for the electrodes modified at $2 \mathrm{D}$ template and in the range of $0.1 \mu \mathrm{M}$ to $800 \mu \mathrm{M}$ with the detection limit $\geq 0.030 \mu \mathrm{M}$ for the electrodes modified at $3 \mathrm{D}$ template.
\end{abstract}

\section{Introduction}

Epinephrine, an important catecholamine neurotransmitter, is necessary for normal functioning of the mammalian central nervous system [1]. Therefore, development of a simple and fast method for its detection and determination is an important task of current neurochemistry. Catecholamines are easily oxidized, thus electrochemical methods appear to be suitable for their quantitative studies [2]. However, the problem is that when it is oxidized directly at the bare electrode, the electrode surfaces get blocked with the final oxidation product. Moreover, catecholamines exist in natural environment together with some small biomolecules like $\mathrm{AA}$ and $\mathrm{UA}$, which oxidize at bare electrodes in almost the same potential region as catecholamine [37]. In recent years, among various attempts to overcome the above-mentioned problems, much attention has been paid to the use of electrodes modified for development of suitable sensors. Literature provides evidence on using glassy carbon electrodes modified by poly(caffeic acid) [7], luminol [8], polyrutine [9], an overoxidized polypyrrole [10], osmium and cobalt hexacyanoferrate $[4,11-13]$, as well as 5-amino-1,3,4-thiadiazole-2-thiol [14] films for the determination of trace amounts of EP with elimination of the interference by AA. The basal plane pyrolytic graphite electrode modified with carbon nanotubes has been used to mediate electrochemical oxidation of EP with elimination of the interference by AA [15]. Furthermore, the electrochemical modification of clenbuterol at paraffin-impregnated graphite electrode [16] and a mesoporous Al-incorporated $\mathrm{SiO}_{2}$ modified electrode [17] have been used successfully for detection of EP. Immobilization of DNA on carbon fibre electrodes by using overoxidized polypyrrole template [18] or deposition of the gold nanoparticles directly on the glassy carbon electrode $[19,20]$ has been tested for selective EP detection in the presence of AA and UA. Moreover, an overoxidized dopamine film deposited on a gold electrode has been successfully tested for selective EP detection in the presence of AA and UA [21]. Recently, electrooxidation of EP in the presence of UA at the $\mathrm{Zn}$ Al layered double hydroxide film modified glassy carbon electrode [22], and multiwalled carbon nanotube modified 
with cobalt phtalocyanine in paraffin composite electrode [23] has been described. The self-assembled monolayers (SAMs) of S-functionalized compounds on polycrystalline gold is a powerful method to prepare a chemical interface with stable and structurally well defined monolayers which exhibit a high degree of orientation, molecular ordering, and packing density [24, 25]. Gold is used frequently as the material for the SAM preparation because of its good affinity to sulphur and its inertness [26]. For example, the electrochemical behaviour of EP has been studied at cysteine [27] SAM-modified gold electrodes. On the other hand, gold nanoparticle modifications could largely increase the immobilized amount of S-functionalized compounds and enhance the Au-S bond and stability of SAMs layer [28]. The electrochemical behaviour of EP has been analysed at the gold nanoparticles assembled on both the dithiothereiol and dodecanethiol mixed layers [29].

In the present study, in search for new materials for detection of catecholamines, the performance of gold electrodes modified with the gold nanoparticle (Au-NPs), dithiodipropionic acid (DTDPA), and cysteamine (CA) is tested. The self-assembled layers were deposited on the planar gold electrode (known as the two-dimensional (2D) electrode and labelled as $\mathrm{Au}$ ) as well as on the nanogold electrode (known as the three-dimensional (3D) Au electrode and labelled as $\mathrm{Au} / \mathrm{Au}-\mathrm{NPs}$ ). The new voltammetric sensors are applied for simultaneous detection of EP, AA, and UA in aqueous solutions.

\section{Experimental}

2.1. Reagents and Chemicals. Dithiodipropionic acid (DTDPA), cysteamine (CA), epinephrine (EP), and auric acid $\left(\mathrm{HAuCl}_{4}\right)$ were purchased from Fluka. Uric acid (UA) and L-ascorbic acid (AA) were obtained from Sigma. $\mathrm{NaH}_{2} \mathrm{PO}_{4}, \mathrm{~K}_{2} \mathrm{HPO}_{4}$, and $\mathrm{NaOH}$ were purchased from Merck. Trisodium citrate, acetone, $\mathrm{H}_{2} \mathrm{SO}_{4}, \mathrm{H}_{2} \mathrm{O}_{2}$, and $\mathrm{C}_{2} \mathrm{H}_{5} \mathrm{OH}$ were from POCG (Gliwice, Poland). All chemicals were obtained of analytical grade quality and were used as obtained without further purification. The solutions were prepared freshly prior to use from deionized water purified in a Millipore Milli-Q system. An Au-colloidal solution was prepared according to procedure described elsewhere [30]. All solutions under investigation were deaerated by blowing highly pure argon through the solution before measurements. The measurements were performed at room temperature.

2.2. Apparatus. The $\mathrm{pH}$ of the solution was measured using a pH-meter (Model-ULAB 2002, TELE-ECO-PROJECT, Poland). The Uv-vis spectra were taken using Cecil (CE 2020, Chemnist, Austria). The reflection-absorption spectra were obtained in an $\mathrm{N}_{2}$ atmosphere on a Brucker $66 \mathrm{v} / \mathrm{S}$ FT-IR spectrometer with an FT-80 grazing angle infrared reflection accessory and a liquid $\mathrm{N}_{2}$ cooled TGS detector. Typically, 2000 scans with $2 \mathrm{~cm}^{-1}$ resolution were performed. Additionally, for comparison the transmission FT-IR spectrum of the DTDPA substrate was recorded on the same spectrometer. The scanning electron microscopy (SEM) analysis was carried out using ZEISS EVO 40 instrument (Germany) with the acceleration voltage of $20 \mathrm{kV}$. The transmission electron microscopy (TEM) image was obtained using JEM-1200 EX2 (Japan) instrument, operating at $200 \mathrm{kV}$. The experimental setups used in voltammetric measurements were the same as those described earlier [31] and included a potentiostat EG-20 (Elpan, Poland), a sine wave generator PW12 (Kabid, Poland), and x-y recorder Endim 620.12 (VEB, Germany).

The electrochemical studies were carried out in a threecompartment cell separated by glass frits. The working electrode was either the bare gold electrode or one of the modified gold electrodes. In all cases, the working electrode was in the shape of a cylinder $(0.5 \mathrm{~mm}$ diameter and $12 \mathrm{~mm}$ length). A gold sheet and the saturated calomel electrode (SCE) were used as auxiliary and reference electrodes, respectively.

2.3. Procedure. Before modification, the bare planar gold electrode (2D) was polished with aluminium slurries of successively decreasing final grades (down to $0.05 \mu \mathrm{m}$, Buehler) on polishing cloths (Buehler). Then, it was rinsed carefully with acetone and water, respectively. After rinsing with water the electrode was electrochemically activated by cycling $\left(v=0.1 \mathrm{~V} \mathrm{~s}^{-1}\right)$ in the potential range between $E=-0.7 \mathrm{~V}$ and $E=0.6 \mathrm{~V}$ versus SCE in the supporting electrolyte $\left(610^{-2} \mathrm{M}\right.$ phosphate buffer, $\left.\mathrm{pH}=7\right)$ until a stable cyclic voltammogram was obtained. This procedure avoids structural changes on the gold surface [32].

In order to obtain a nanogold electrode, the activated 2D Au electrode was immersed in the colloidal gold solution (sol $\mathrm{Au}$ ) for $24 \mathrm{~h}$ at $4^{\circ} \mathrm{C}$. The template obtained was called the three-dimensional (3D) Au electrode and marked as Au/AuNPs. To form the DTDPA self-assembled layers on the Au or $\mathrm{Au} / \mathrm{Au}-\mathrm{NPs}$ surfaces, the respective templates were immersed in $5 \mathrm{mM}$ ethanolic solution of DTDPA. In order to endow the SAM layers with Au-NPs particles the templates obtained were immersed firstly in a $2 \mathrm{mM}$ solution of $\mathrm{CA}$ at $4^{\circ} \mathrm{C}$ and next in the sol Au solution at $4^{\circ} \mathrm{C}$. The modified electrodes were prepared according to the following scheme:

$$
\begin{aligned}
& \text { Au/Au-NPs: }(\mathrm{Au} \stackrel{24 \mathrm{~h}}{\longrightarrow} \text { sol Au); } \\
& \text { Au/DTDPA: }(\mathrm{Au} \stackrel{10 \mathrm{~h}}{\longrightarrow} \text { DTDPA }) ; \\
& \text { Au/DTDPA/CA/Au-NPs: }(\mathrm{Au} \stackrel{10 \mathrm{~h}}{\longrightarrow} \mathrm{DTDPA} \stackrel{4 \mathrm{~h}}{\longrightarrow} \mathrm{CA} \stackrel{24 \mathrm{~h}}{\longrightarrow} \\
& \text { sol Au); } \\
& \text { Au/Au-NPs/DTDPA: }(\mathrm{Au} \stackrel{24 \mathrm{~h}}{\longrightarrow} \operatorname{sol} \mathrm{Au} \stackrel{10 \mathrm{~h}}{\longrightarrow} \mathrm{DTDPA}) ; \\
& \text { Au/Au-NPs/DTDPA/CA/Au-NPs: }(\mathrm{Au} \stackrel{24 \mathrm{~h}}{\longrightarrow} \operatorname{sol~Au} \stackrel{10 \mathrm{~h}}{\longrightarrow} \\
& \text { DTDPA } \stackrel{4 \mathrm{~h}}{\longrightarrow} \mathrm{CA} \stackrel{24 \mathrm{~h}}{\longrightarrow} \text { sol Au }) .
\end{aligned}
$$

The modified electrodes were stored in phosphate buffer at $4^{\circ} \mathrm{C}$. Before each use, they were washed by water and dried in argon stream. The self-assembled layers were removed from the modified electrode surfaces by dipping them in the Piranha solution for 10 minutes and rinsing with water. Next the procedure of polishing, activation and modifications of the bare Au electrodes repeated. 


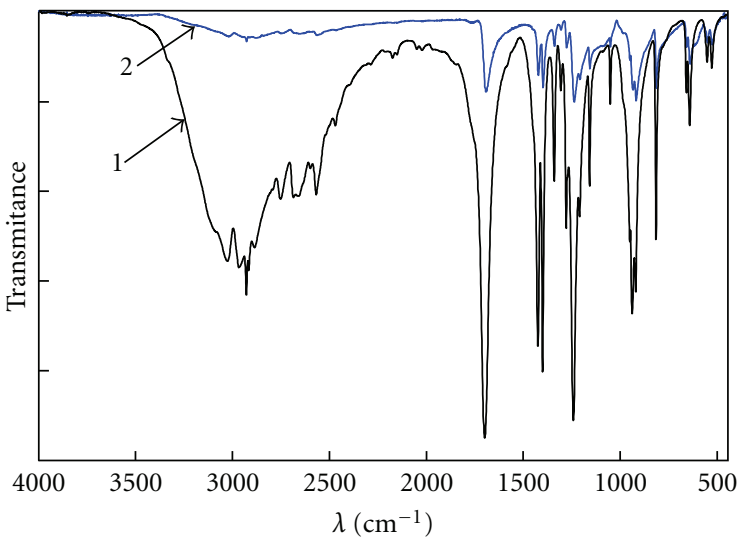

(a)

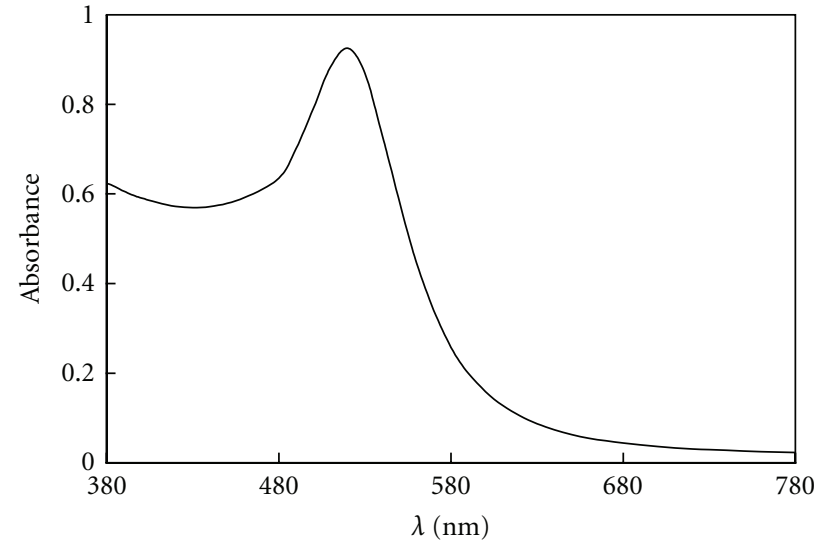

(b)

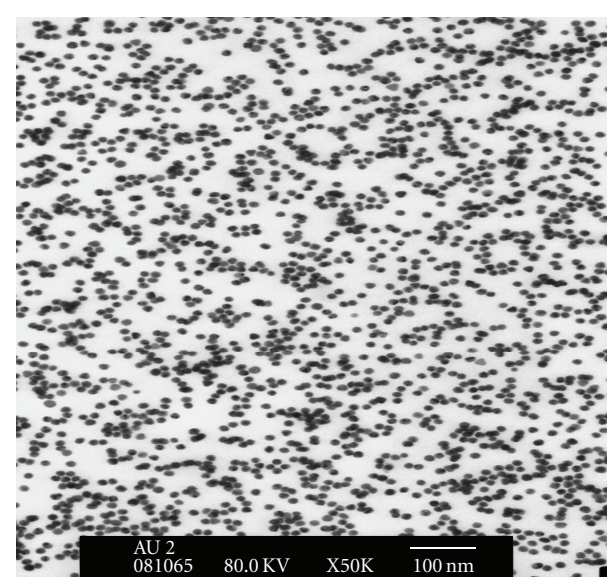

(c)

FIgUre 1: (a) The transmission FT-IR spectra (1) the reflectance spectra of compounds adsorbed on the Au plate (2) and for DTDPA. (b) Optical UV-Vis spectrum of the colloidal Au solution. (c) Transmission electron image of the gold nanoparticles.

\section{Results and Discussion}

3.1. Characterization of the Modified Electrodes. Figure 1(a) compares of the infrared reflection spectrum of Au surface with adsorbed DTDPA (spectrum 1) with the transmission FT-IR spectrum of the liquid DTDPA (spectrum 2). The reflection-absorption spectrum presented in Figure 1(a) proves that the SAM layers are present at the gold electrode surface. It is commonly known that gold have a high affinity for the $\mathrm{S}$ atoms and the formation of self-assembled layers from disulfides is based on the reaction [24, 3336]: $\mathrm{R}-\mathrm{S}-\mathrm{S}-\mathrm{R}+\mathrm{Au}_{n}^{0} \rightarrow 2 \mathrm{RS}^{-} \mathrm{Au}^{+} \cdot \mathrm{Au}_{n}^{0}$. Per analogy to disulfides, the SAMs formation by adsorption of DTDPA on the gold template occur via the same mechanism $\mathrm{HOOC}-\mathrm{R}-\mathrm{S}-\mathrm{S}-\mathrm{R}-\mathrm{COOH}+\mathrm{Au}_{n}^{0} \rightarrow 2 \mathrm{HOOC}-\mathrm{RS}^{-} \mathrm{Au}^{+} \cdot \mathrm{Au}_{n}^{0}$. The attachment of DTDPA to Au surface has been possible due to strong chemisorption of DTDPA as a result of the formation of two bonds with Au after the S-S bond cleavage [37].

The diameter of the gold nanoparticles prepared was estimated by Uv-vis analysis whose results are presented in Figure 1(b). As seen, the colloidal gold gives the maximum absorbance close to $520 \mathrm{~nm}$. This is in agreement with literature data, as it has been shown that the $\mathrm{Au}$ nanoparticles of diameters between $2.6 \mathrm{~nm}$ and $20 \mathrm{~nm}$ could be expected when the absorption maximum appears between $514 \mathrm{~nm}$ and $530 \mathrm{~nm}$, respectively $[38,39]$. The transmission electron microscopy image (TEM) shown in Figure 1(c) allowed evaluation of the average diameter of the Au-NPs particles in the gold sol solution used as $14 \mathrm{~nm}$.

The difference between 2- and 3-dimensional modified electrodes lies in the fact that in the former case, the modified reagent DTDPA is deposited directly on the bare gold template, whereas in the second case before DTDPA deposition, the bare gold template has been decorated by a layer of gold nanoparticles. The gold nanoparticles are attached to the substrate surface by directly dipping the gold template into gold solution, and gold nanoparticlesmodified electrodes have been obtained without using binder molecules [40]. The Au-NPs layer is formed making use of the electrostatic interactions as the gold nanoparticles stabilised with citrate, used in the present study, are endowed with negative charge $[41,42]$. On $2 \mathrm{D}$ template, the Scontaining acids form a well-organized two-dimensional compact layers, whereas on $3 \mathrm{D}$ template, they form a three dimensional layers which adopt a more disordered structure as compared to that obtained on $2 \mathrm{D}$ template [43]. In both cases, cysteamine is deposited later in consecutive steps of modifications. Hydrogen bonds form between carboxylic 

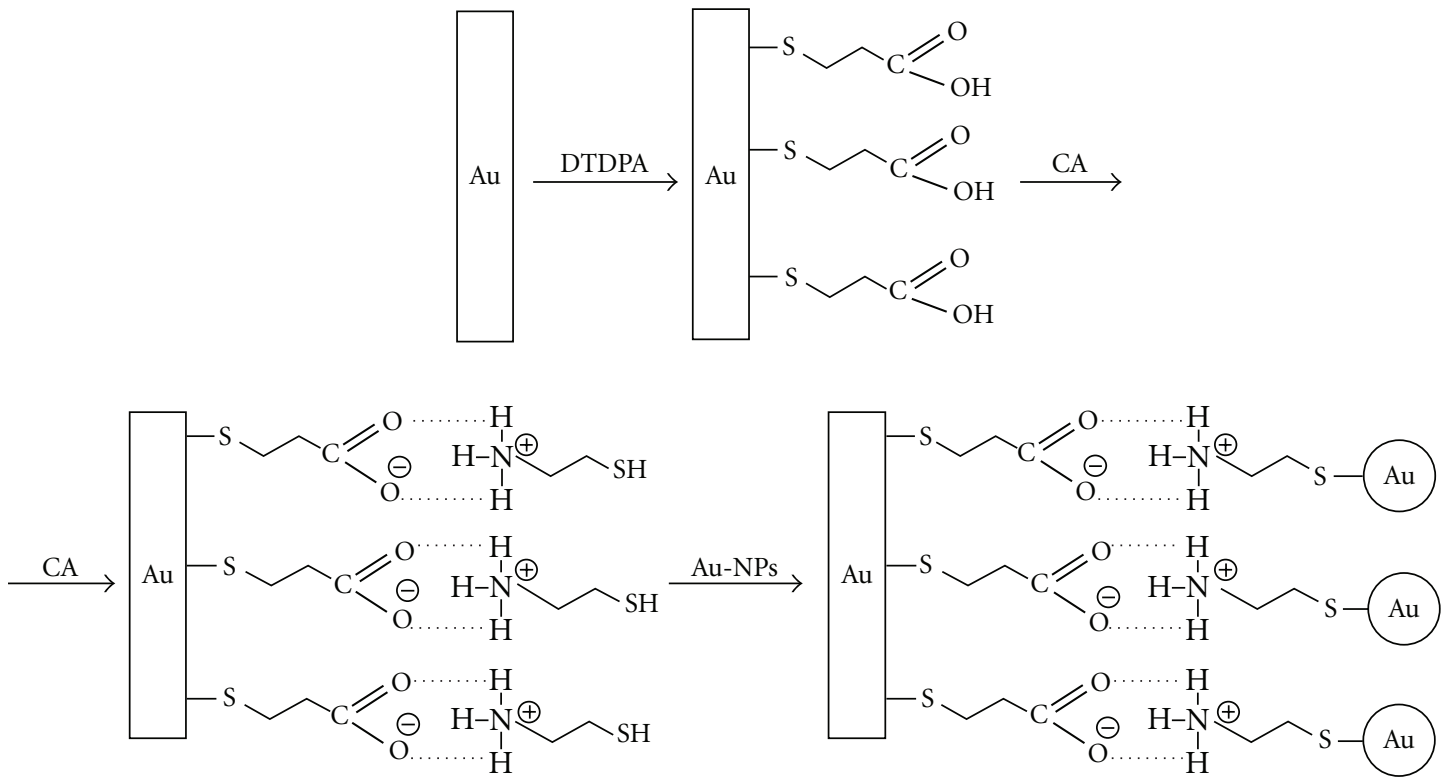

(a) 2D structure
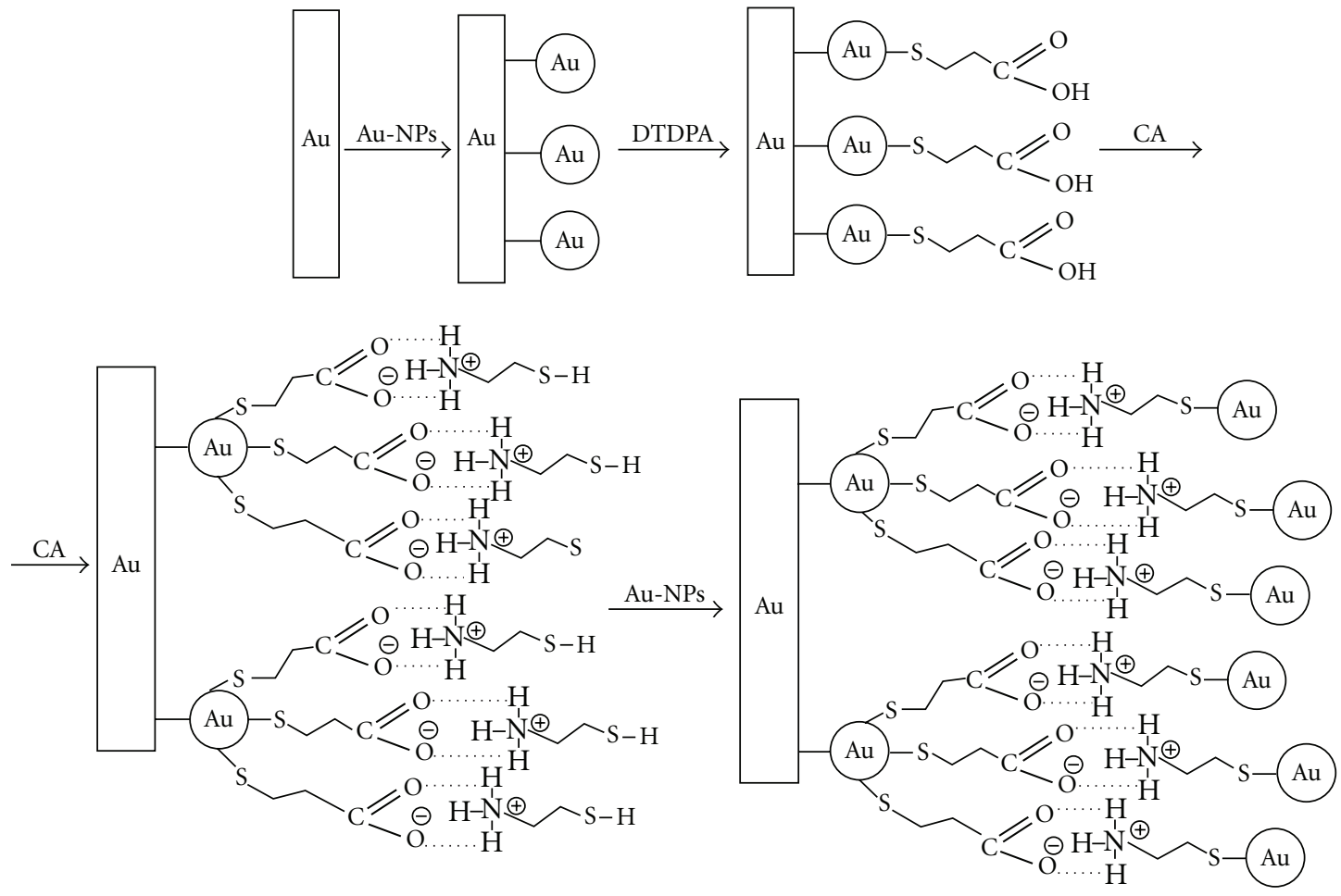

(b) $3 \mathrm{D}$ structure

Figure 2: Schematic representation of the surface modifications of the gold electrode for (a) the 2D and (b) 3D gold template.

groups in the acid and amine group in cysteamine, and as a result, the respective salt is formed. In next step of the modification, Au-NPs are deposited on the templates prepared. To illustrate particular stages of modification of the gold electrodes of 2D and 3D structure, the relevant schemes are presented in Figure 2. Moreover, Figure 3 compares the results of the SEM analysis of morphological changes in the gold template resulting from the electrode modification process. The micrographs presented confirm that the layers obtained on the 2D template are more compact as compared with those obtained on 3D template.

3.2. Oxidation of Epinephrine at Bare Gold Electrode Pure and Modified with Gold Nanoparticles and S-Functionalized SelfAssembled Layers. EP oxidation at the bare gold electrode proceeds in two potential ranges. The irreversible anodic 
$\mathrm{Au}$

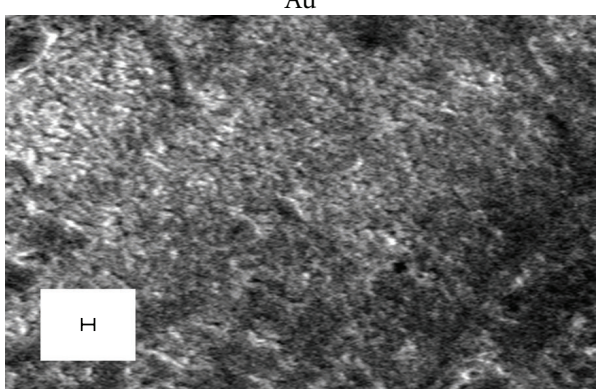

(a)

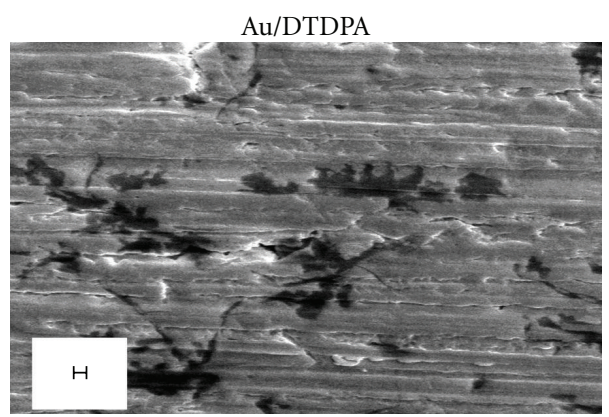

(c)

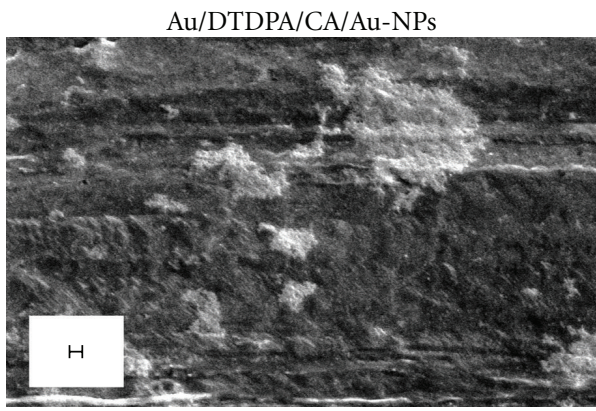

(e)

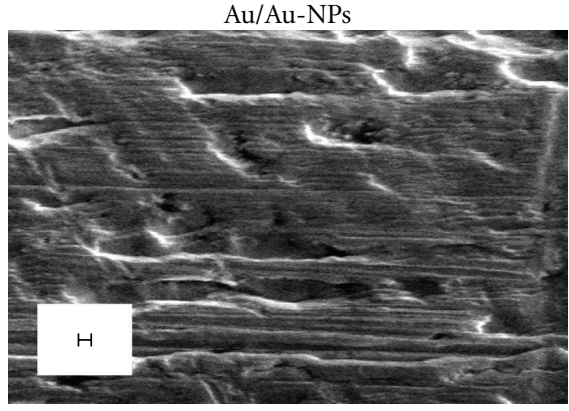

(b)

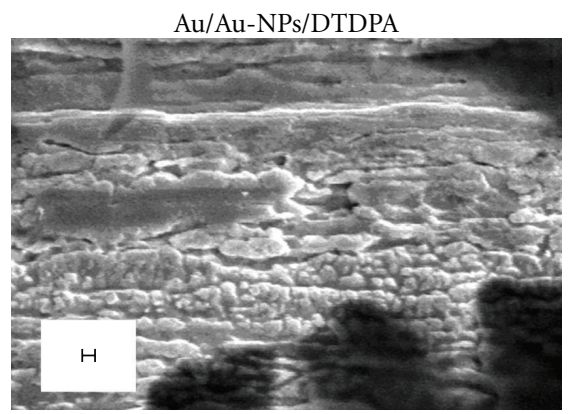

(d)



(f)

Figure 3: Scanning electron micrographs of the bare Au surface and surfaces modified by deposition of Au-NPs, CA, and DTDPA. Magnification: $10000 \mathrm{x}$; accelerating voltage: $20 \mathrm{kV}$. Scale bar: $2 \mu \mathrm{m}$.

peak (IA) at $E=0.3 \mathrm{~V}$ is assigned to $\mathrm{EP}$ oxidation to epinephrinequinone, whereas the couple of peaks at $-0.07 \mathrm{~V}$ and $-0.13 \mathrm{~V}$ in the anodic (IIA) and cathodic (IIC) scan, respectively, are related to reversible oxidation of leucoepinephrinechrome to epinephrinechrome after cyclization of epinephrinequinone via a 1,4-Michael addition [44], Figure 4(a).

In evaluation of the catalytic effect of different electrodes on the electrooxidation process, two factors should be considered: a decrease in the overpotential of oxidation and an increase in the current density. Figure 3 compares the voltammetric response of a bare gold electrode in the presence of EP with those obtained at the electrodes modified at 2D gold template: Au/DTDPA, and Au/DTDPA/CA/AuNPs (Figure 4(a)) and at 3D gold template: $\mathrm{Au} / \mathrm{Au}-\mathrm{NPs}$, $\mathrm{Au} / \mathrm{Au}-\mathrm{NP}$ /DTDPA, and Au/Au-NPs/DTDPA/CA/Au-NPs (Figure 4(b)). In Figure 3, greater catalytic effect is achieved for EP oxidation at modified electrodes prepared on $3 \mathrm{D}$ template-the current densities as well as the decrease in the overpotential of each peak are greater than those obtained at the electrodes modified on 2D gold template. A favourable catalytic activity of gold nanoparticle arrays towards EP oxidation may be connected with the fact that the electron transfer between EP and the electrode is more effective in three-dimensional acid layers compared with that in two-dimensional acid layers. The more disordered threedimensional monolayers probably ensure better penetration of the reactant through the alkane chains on nanoparticle surface because of their curvature [43]. This is in accordance with the observation that the SAMs film permeability was observed to decrease with increasing substrate smoothness [45].

3.2.1. Effect of $p H$ on Oxidation of Epinephrine on Modified Gold Electrodes. EP is protonated and positively charged at physiological $\mathrm{pH}\left(\mathrm{p} K_{\mathrm{a}}=9.9\right)$ [46]. The electrochemical response of the modified electrodes towards EP electrooxidation has been studied in the $\mathrm{pH}$ range between 2 and 13 . 


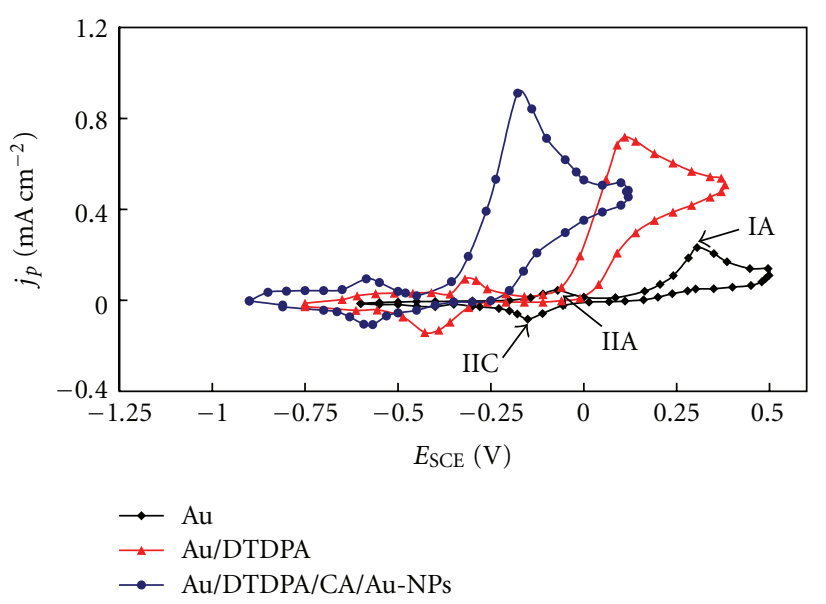

(a)

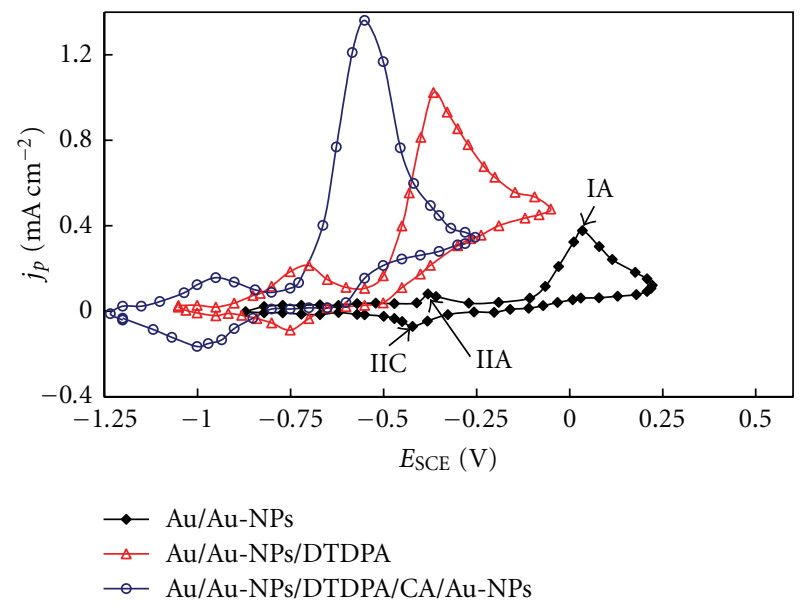

(b)

Figure 4: Cyclic voltammograms of pure and modified gold electrodes at (a) 2D and (b) 3D template in $60 \mathrm{mM}$ phosphate buffer $(\mathrm{pH}=7)$ with $500 \mu \mathrm{M}$ EP. $v=0.1 \mathrm{~V} \mathrm{~s}^{-1}$.

Analysis of variation of the peak potential $E_{p}$ assigned to $\mathrm{EP}$ to epinephrinequinone electrooxidation with $\mathrm{pH}$ of the supporting electrolyte has suggested that the overall process is proton dependent. It was observed that the peak potential shifts negatively with increasing $\mathrm{pH}$. The linear regression provided a slope of $0.058 \mathrm{~V}$ for $\mathrm{Au}$ electrode, whereas for all modified electrodes, a slope of $d \mathrm{pH} / d E_{p}$ was comprised between 0.058 and 0.061 per unit $\mathrm{pH}$ with the confidence intervals $\leq \pm 0.002 \mathrm{~V}\left(R^{2} \geq 0.994, n=7\right)$. The magnitudes of the $d E_{p} / d \mathrm{pH}$ slopes are very close to the theoretical Nernstian value of $0.059 \mathrm{~V} \mathrm{[47]} \mathrm{and} \mathrm{indicate} \mathrm{that} \mathrm{the} \mathrm{electron}$ transfer step is preceded by a protonation with the same number of protons involved in the EP oxidation mechanism, regardless of the template $2 \mathrm{D}$ or $3 \mathrm{D}$ used for electrode modifications. Moreover, the current peak density $\left(j_{p}\right)$ was observed to change with the solution $\mathrm{pH}$, and the maximum current densities were obtained in the $\mathrm{pH}$ range between 6 and 8. The electrochemical analysis of EP on the modified gold electrodes prepared was carried out in a solution of $\mathrm{pH}$ 7. This $\mathrm{pH}$ value has been chosen taking into regard the prospective practical application of electrodes prepared in biological systems.
3.2.2. Effect of the Potential Sweep Rates on the Oxidation Peak Current of Epinephrine on Modified Gold Electrodes. The information on electrooxidation of EP on the electrodes prepared was obtained by investigating this process at different potential sweep rates $(v)$. A linear relationship of the peak current density $\left(j_{p}\right)$ versus the square root of the scan rate $\left(v^{1 / 2}\right)$ was obtained in the $v$ range from $0.01 \mathrm{~V} \mathrm{~s}^{-1}$ to $0.2 \mathrm{~V} \mathrm{~s}^{-1}$. It means that the electron transfer process at the modified electrode is diffusion controlled, which is favourable for quantitative applications [46]. From the kinetic theory of the electrode reaction, for the pure diffusion controlled process, the value of $d \log j_{p} / d \log v$ slope should be 0.5 , while for the pure adsorption controlled process, it should be 1 . The values of the $\log j_{p} / d \log v$ parameter obtained in this work additionally confirmed that the process studied was diffusion rate controlled. The magnitude of the slope of $d \log j_{p} / d \log v$ obtained was 0.51 for the Au electrode, while for all modified electrodes, a slope of $d \log j_{p} / d \log v$ was comprised between 0.48 and 0.51 with the confidence intervals lower than $\leq \pm 0.01\left(R^{2} \geq 0.998\right.$; $n=15)$.

3.2.3. Oxidation of Epinephrine at the Bare Gold and the Gold Modified Electrodes in the Presence of Ascorbic and Uric Acids. As mentioned in the introduction, and as shown in Figure 5, the detection of biogenic amines on the bare gold electrode is interfered by the coexistence of both AA and UA. The oxidation peaks of EP, AA and UA overlap, Figure 5(a). This problem does not appear when EP is oxidized on the modified electrodes used in this work; see Figures 5(b)-5(f). It is evident that in the ternary mixture containing $500 \mu \mathrm{M}$ of EP, $1000 \mu \mathrm{M}$ of $\mathrm{AA}$, and $1000 \mu \mathrm{M} \mathrm{UA}$, the oxidation peaks of these compounds are clearly separated from each other, as compared with the cyclic voltammogram recorded for such a mixture of compounds at the bare gold electrode. Since at $\mathrm{pH}=7 \mathrm{EP}$ exists in its cationic form $\left(\mathrm{p} K_{\mathrm{a}}=9.9\right.$ [46], while AA $\left(\mathrm{p} K_{\mathrm{a}}=4.1\right)[21]$ and $\mathrm{UA}\left(\mathrm{p} K_{\mathrm{a}}=5.4\right)[21]$ in their anionic forms, thus the positive potential shift of the peak currents of AA and UA is attributed to a repulsive interaction between the negatively charged of AA and UA in solution at pH 7 and the negatively charged $\mathrm{COO}^{-}$group of DTDPA layer and $\mathrm{Au}$ nanomolecules stabilised by citrate [42]. The electrostatic attraction between the positively charged EP and the negatively charged modified layers would be the reason for the shift of the peak current of EP towards more negative potential values for all modified electrodes used.

Because the modified electrodes prepared can successfully distinguish EP, AA, and UA oxidation peaks and thus are suitable for electrochemical analysis of EP without the interference of AA and UA, the experiment was made in which the concentration of one compound was changed, whereas those of two other ones were kept constant. The concentration of EP was changed in the range $0.1 \mu \mathrm{M}$ to $1000 \mu \mathrm{M}$, Figure $6(\mathrm{a})$, while the concentration of AA and UA was changed in the range $500 \mu \mathrm{M}$ to $5000 \mu \mathrm{M}$, Figures 6 (b) and $6(\mathrm{c})$. For all electrodes modified studied, the current density of the compound whose concentrations was changed increased proportionally to its concentration in the solution, whereas the peak currents of two other compounds whose 


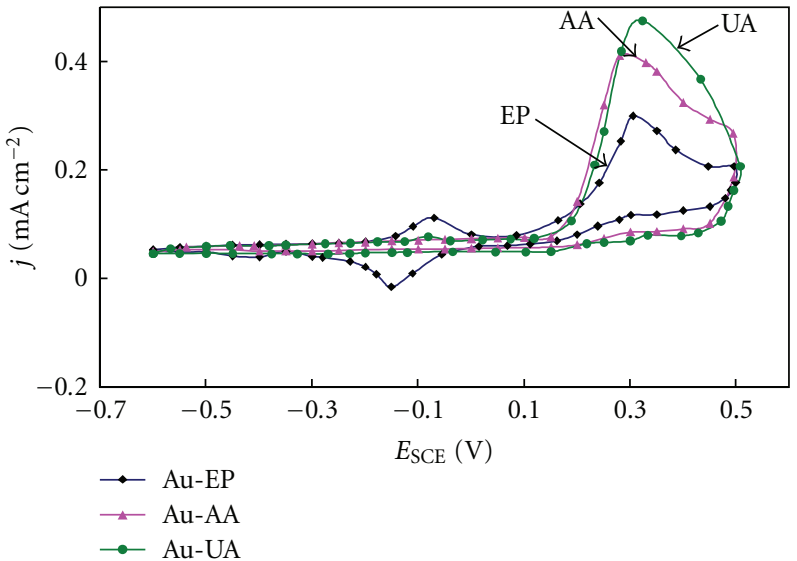

(a)



$\rightarrow$ Au/DTDPA/CA/AU-NPs-EP

$\leadsto \mathrm{Au} / \mathrm{DTDPA} / \mathrm{CA} / \mathrm{AU}-\mathrm{NP}$-EP + AA + UA

(c)

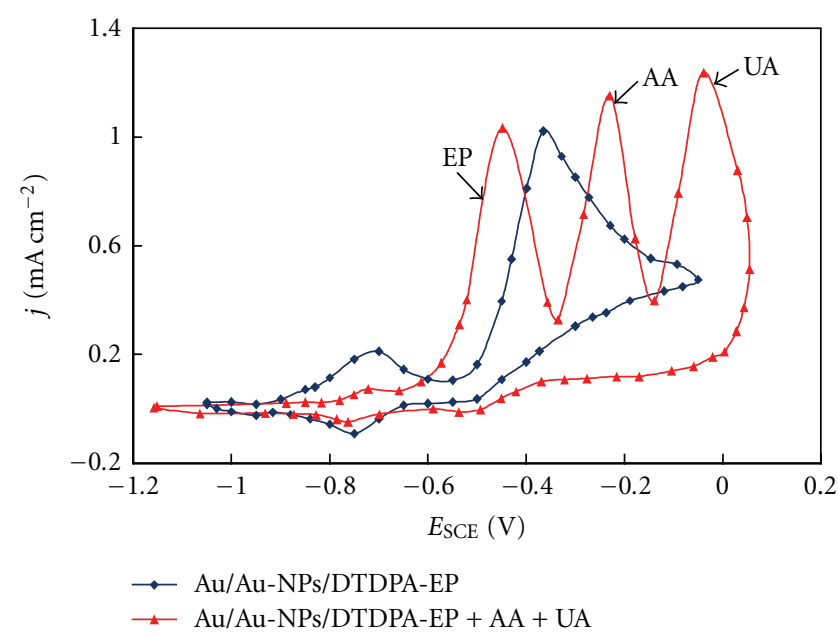

(e)

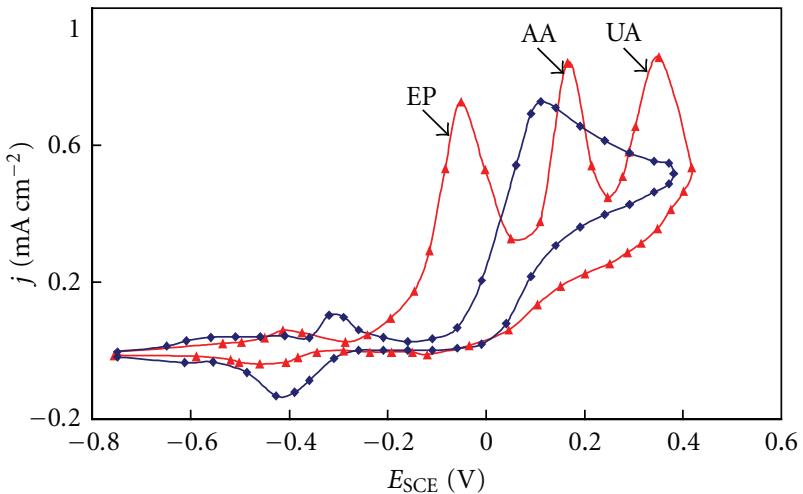

$\rightarrow$ Au/DTDPA-EP + AA + UA

$\rightarrow$ Au/DTDPA-EP

(b)

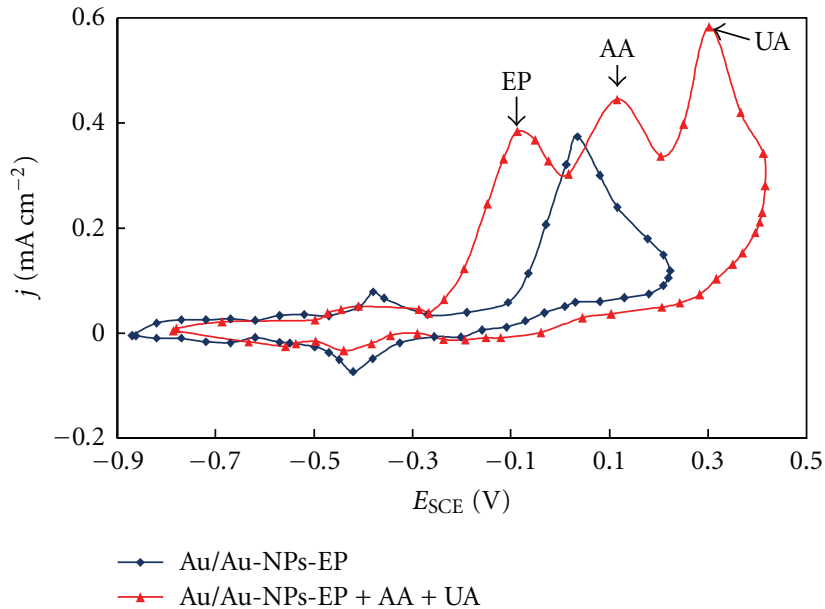

(d)

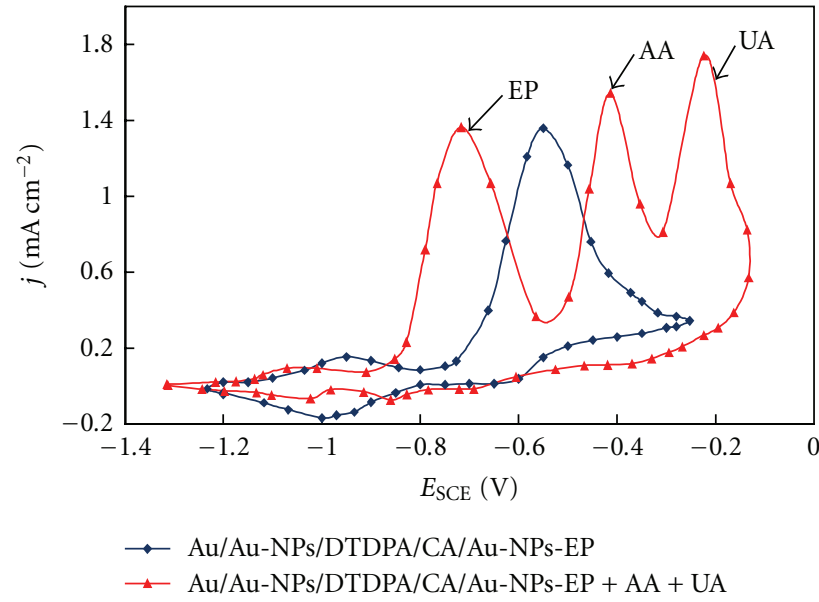

(f)

Figure 5: Cyclic voltammograms of pure (a) and modified gold electrodes (b-f) in $60 \mathrm{mM}$ phosphate buffer, $\mathrm{pH}=7$ in a mixture of $500 \mu \mathrm{M}$ $\mathrm{EP}+1000 \mu \mathrm{M}$ of $\mathrm{AA}+1000 \mu \mathrm{M}$ UA. For comparison, each figure presents the cyclic voltammograms in $60 \mathrm{mM}$ phosphate buffer, $\mathrm{pH}=7$ with $500 \mu \mathrm{M}$ EP alone for a respective electrode. $v=0.1 \mathrm{~V} \mathrm{~s}^{-1}$. 
TABLE 1: Calibration curve parameters for determination of EP, AA and UA on modified gold electrodes. $v=0.1 \mathrm{~V} \mathrm{~s}^{-1}$.

\begin{tabular}{|c|c|c|c|c|}
\hline Electrode & Compound & Regression equation & $R^{2}(n)$ & Detection limit $c_{L} / \mu \mathrm{M}$ \\
\hline \multirow{3}{*}{$\mathrm{Au} / \mathrm{DTDPA}$} & $\mathrm{EP}$ & $j_{p}=(42 \pm 3) 10^{-3}+(139 \pm 4) 10^{-5} c_{\mathrm{EP}}[\mu M]$ & $0.9980(n=17)$ & 0.045 \\
\hline & AA & $j_{p}=(175 \pm 6) 10^{-3}+(630 \pm 4) 10^{-6} c_{\mathrm{AA}}[\mu M]$ & $0.9981(n=10)$ & 14 \\
\hline & UA & $j_{p}=(224 \pm 6) 10^{-3}+(694 \pm 8) 10^{-6} c_{\mathrm{UA}}[\mu M]$ & $0,9990(n=10)$ & 12 \\
\hline \multirow{3}{*}{$\mathrm{Au} / \mathrm{DTDPA} / \mathrm{CA} / \mathrm{Au}-\mathrm{NPs}$} & $\mathrm{EP}$ & $j_{p}=(60 \pm 6) 10^{-3}+(167 \pm 3) 10^{-5} c_{\mathrm{EP}}[\mu M]$ & $0.9975(n=17)$ & 0.034 \\
\hline & AA & $j_{p}=(179 \pm 6) 10^{-3}+(773 \pm 8) 10^{-6} c_{\mathrm{AA}}[\mu M]$ & $0.9973(n=10)$ & 9 \\
\hline & UA & $j_{p}=(180 \pm 4) 10^{-3}+(1040 \pm 7) 10^{-6} c_{\mathrm{UA}}[\mu M]$ & $0.9984(n=10)$ & 8 \\
\hline \multirow{3}{*}{$\mathrm{Au} / \mathrm{Au}-\mathrm{NPs}$} & $\mathrm{EP}$ & $j_{p}=(29 \pm 4) 10^{-3}+(74 \pm 1) 10^{-5} c_{\mathrm{EP}}[\mu M]$ & $0.9958(n=18)$ & 0.069 \\
\hline & $\mathrm{AA}$ & $j_{p}=(32 \pm 1) 10^{-3}+(476 \pm 3) 10^{-6} c_{\mathrm{AA}}[\mu M]$ & $0.9997(n=10)$ & 11 \\
\hline & UA & $j_{p}=(26 \pm 4) 10^{-3}+(600 \pm 14) 10^{-6} c_{\mathrm{UA}}[\mu M]$ & $0.9961(n=10)$ & 8 \\
\hline \multirow{3}{*}{$\mathrm{Au} / \mathrm{Au}-\mathrm{NPs} / \mathrm{DTDPA}$} & $\mathrm{EP}$ & $j_{p}=(230 \pm 4) 10^{-3}+(159 \pm 7) 10^{-5} c_{\mathrm{EP}}[\mu M]$ & $0.9997(n=18)$ & 0.035 \\
\hline & AA & $j_{p}=(56 \pm 2) 10^{-3}+(1116 \pm 12) 10^{-6} c_{\mathrm{AA}}[\mu M]$ & $0.9996(n=10)$ & 7 \\
\hline & UA & $j_{p}=(147 \pm 5) 10^{-3}+(1174 \pm 14) 10^{-6} c_{\mathrm{UA}}[\mu M]$ & $0.9981(n=10)$ & 5 \\
\hline \multirow{3}{*}{$\mathrm{Au} / \mathrm{Au}-\mathrm{NPs} / \mathrm{DTDPA} / \mathrm{CA} / \mathrm{Au}-\mathrm{NPs}$} & $\mathrm{EP}$ & $j_{p}=(370 \pm 5) 10^{-3}+(191 \pm 3) 10^{-5} c_{\mathrm{EP}}[\mu M]$ & $0.9991(n=18)$ & 0.03 \\
\hline & $\mathrm{AA}$ & $j_{p}=(82 \pm 5) 10^{-3}+(1264 \pm 16) 10^{-6} c_{\mathrm{AA}}[\mu M]$ & $0.9997(n=10)$ & 7 \\
\hline & UA & $j_{p}=(176 \pm 4) 10^{-3}+(1210 \pm 25) 10^{-6} c_{\mathrm{UA}}[\mu M]$ & $0.9994(n=10)$ & 4 \\
\hline
\end{tabular}

contents were not changed remained constant. Moreover, in the experiments in which the concentrations of EP, AA, and UA were changed at the same time, the peak current density for those three compounds increased simultaneously linearly with their concentration without interfering interrelations. The respective regression equations expressing the linearity between $j_{p}$ and $c_{\mathrm{EP}}$ obtained on each electrode studied are collected in Table 1. Besides the regression equations, values of the coefficient $R^{2}$ defined, the linearity [48] are included in Table 1. Moreover, Table 1 gives the detection limit $\left(c_{L}\right)$ estimated according to the formula recommended by IUPAC $c_{L}=k s_{b} / S$ [48] (where $s_{b}$ is the standard deviation of the current density of the supporting electrolyte solution, $S$ is the slope of the straight line, and $k=3$ is a numerical constant). Furthermore, Table 1 presents the respective regression equations expressing the linearity between $j_{p}$ and $c_{\mathrm{AA}}$ as well as $j_{p}$ and $c_{\mathrm{UA}}$ obtained on each electrode studied.

It has been established that the relationships between the peak current density $\left(j_{p}\right)$ of EP to epinephrinequinone electrooxidation versus EP concentration $\left(c_{\mathrm{EP}}\right)$ obtained on a bare gold electrode was linear in the range of $1 \mu \mathrm{M}$ to $500 \mu \mathrm{M}$ of EP. This concentration range is expanded from $0.1 \mu \mathrm{M}$ to $700 \mu \mathrm{M}$ when $\mathrm{EP}$ is oxidized on Au/DTDPA and Au/DTDPA/CA/Au-NPs electrodes. Moreover, for the electrodes $\mathrm{Au} / \mathrm{Au}-\mathrm{NPs}, \mathrm{Au} / \mathrm{Au}-\mathrm{NPs} / \mathrm{DTDPA}$, and $\mathrm{Au} / \mathrm{Au}-$ NPs/DTDPA/CA/Au-NPs, the relation between $j_{p}$ and $c_{\mathrm{EP}}$ is linear in the range of $0.1 \mu \mathrm{M}$ to $800 \mu \mathrm{M}$ of EP. The results observed prove that the modified gold electrodes enhance the sensitivity towards EP detection. It is worth noting that the range of concentrations over which the EP content can be reliably estimated on the basis of the regression equation is broader than those reported in literature $[6,7,9,10,17-$ $22,27]$. Moreover, the EP detection limit achieved in this study with the use of the modified electrodes is lower than that obtained in $[6,7,9,18,19,22,27]$. From the data collected in Table 1, it is evident that the detection limit of EP was lower when the electrode modification was carried out at $3 \mathrm{D}$ template. Moreover, when gold nanoparticles were at the end of the modified layer, the detection limit was also lower as compared with the results obtained at the electrodes without Au-NPs at the end of the modified layer. In any case, the presence of Au-NPs layer in the structure of the modified electrodes contributes to lowering of the detection limit of amine studied.

3.3. Electrode Reproducibility and Stability of the Modified Electrodes. The stability of the modified electrodes was checked by measuring their voltammetric response on EP electrooxidation from day to day. Between each subsequent measurement, the electrodes prepared were stored in phosphate buffer at $4^{\circ} \mathrm{C}$. In 5 weeks, the voltammetric responses for the $500 \mu \mathrm{M}$ EP solutions decreased by about $9 \%, 7 \%$, $7 \%, 6 \% ; 7 \%, 5 \%$, and $3 \%$ of their initial responses for the Au, Au/DTDPA, Au/DTDPA/CA/Au-NPs, Au/Au-NPs, $\mathrm{Au} / \mathrm{Au}-\mathrm{NPs} / \mathrm{DTDPA}$, and $\mathrm{Au} / \mathrm{Au}-\mathrm{NPs} / \mathrm{DTDPA} / \mathrm{CA} / \mathrm{Au}-\mathrm{NPs}$ electrode, respectively.

To characterize the reproducibility of the prepared modified gold electrodes, repetitive measurements were carried out in a solution containing $500 \mu \mathrm{M}$ of EP. The relative standard deviations (RDS) of voltammetric responses for 10 successive determination on $\mathrm{Au}, \mathrm{Au} / \mathrm{DTDPA}, \mathrm{Au} /$ DTDPA/CA/Au-NPs, Au/Au-NPs, Au/Au-NPs/DTDPA, and $\mathrm{Au} / \mathrm{Au}-\mathrm{NPs} / \mathrm{DTDPA} / \mathrm{CA} / \mathrm{Au}-\mathrm{NPs}$ electrode were 4\%, 4\%, $4 \%, 3 \%, 3 \%$, and $2 \%$, respectively.

\section{Conclusions}

The results of the study presented here have demonstrated that the oxidation kinetic of EP, a compound of biological importance, on gold surfaces modified with gold nanoparticles, cysteamine, and dithiodipropionic acid was enhanced with comparison to the electrochemical activity of EP at the bare gold electrode. The prepared sensors exhibited excellent stability and reproducibility. The novel modified electrodes are characterised with good selectivity and electroactivity to EP oxidation in voltammetric measurements in 


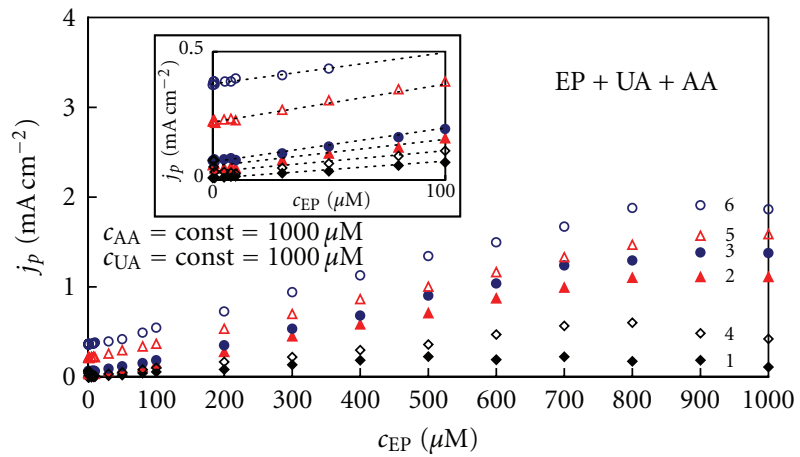

(a)

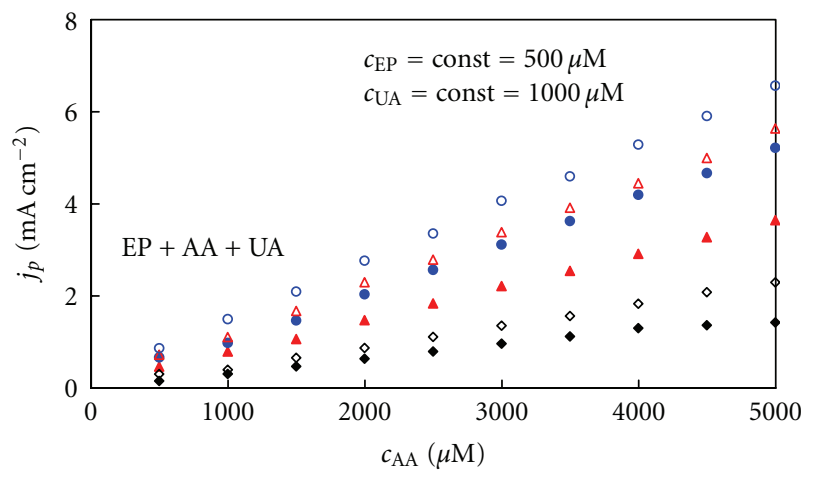

(b)

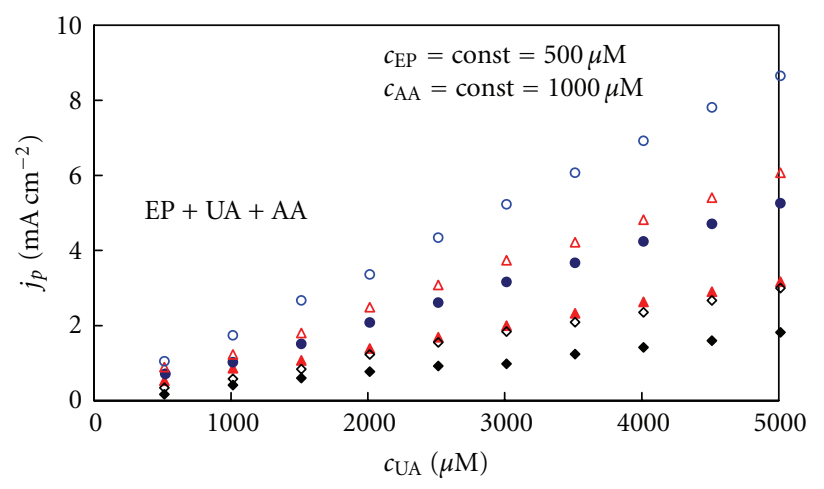

- 1: Au

- 2: Au/DTDPA

- 3: Au/DTDPA/CA/Au-NPs

$\diamond$ 4: Au/Au-NPs

$\triangle$ 5: Au/Au-NPs/DTDPA

- 6: Au/Au-NPs/DTDPA/CA/Au-NPs

(c)

FIGURE 6: The peak current density versus (a) EP; (b) AA and (c) UA concentration in $60 \mathrm{mM}$ phosphate buffer $(\mathrm{pH}=7)$ for modified gold electrodes. $v=0.1 \mathrm{~V} \mathrm{~s}^{-1}$.

the presence of interfering compounds, which is favourable for the detection of EP in physiological environment.

\section{Acknowledgment}

Financial support of this work by the Ministry of Scientific Research and Information Technology, Poland, is gratefully acknowledged.

\section{References}

[1] T. Nogrady and D. F. Weaver, Medical Chemistry. A Molecular and Biochemical Aproach, Oxford University Press, New York, NY, USA, 2005.

[2] M. D. Hawley, S. V. Tatawawadi, S. Piekarski, and R. N. Adams, "Electrochemical studies of the oxidation pathways of catecholamines," Journal of the American Chemical Society, vol. 89, no. 2, pp. 447-450, 1967.

[3] M. A. Dayton, A. G. Ewing, and R. M. Wightman, "Response of microvoltammetric electrodes to homogeneous catalytic and slow heterogeneous charge-transfer reactions," Analytical Chemistry, vol. 52, no. 14, pp. 2392-2396, 1980.

[4] J. A. Ni, H. X. Ju, H. Y. Chen, and D. Leech, "Amperometric determination of epinephrine with an osmium complex and Nafion double-layer membrane modified electrode," Analytica Chimica Acta, vol. 378, pp. 151-157, 1999.

[5] J. Chen and C. S. Cha, "Detection of dopamine in the presence of a large excess of ascorbic acid by using the powder microelectrode technique," Journal of Electroanalytical Chemistry, vol. 463, no. 1, pp. 93-99, 1999.

[6] H. M. Zhang, X. L. Zhou, R. T. Hui, N. Q. Li, and D. P. Liu, "Studies of the electrochemical behavior of epinephrine at a homocysteine self-assembled electrode," Talanta, vol. 56, no. 6, pp. 1081-1088, 2002.

[7] W. Ren, H. Q. Luo, and N. B. Li, "Simultaneous voltammetric measurement of ascorbic acid, epinephrine and uric acid at a glassy carbon electrode modified with caffeic acid," Biosensors and Bioelectronics, vol. 21, no. 7, pp. 1086-1092, 2006.

[8] S. M. Chen and K. C. Lin, "The electrocatalytic properties of biological molecules using polymerized luminol filmmodified electrodes," Journal of Electroanalytical Chemistry, vol. 523, no. 1-2, pp. 93-105, 2002.

[9] G. P. Jin, Q. Z. Chen, Y. F. Ding, and J. B. He, "Electrochemistry behavior of adrenalin, serotonin and ascorbic acid at novel poly rutin modified paraffin-impregnated graphite electrode," Electrochimica Acta, vol. 52, no. 7, pp. 2535-2541, 2007.

[10] J. Li and X. Q. Lin, "Electrodeposition of gold nanoclusters on overoxidized polypyrrole film modified glassy carbon electrode and its application for the simultaneous determination of epinephrine and uric acid under coexistence of ascorbic acid," Analytica Chimica Acta, vol. 596, no. 2, pp. 222-230, 2007.

[11] S. M. Chen and K. T. Peng, "The electrochemical properties of dopamine, epinephrine, norepinephrine, and their electrocatalytic reactions on cobalt(II) hexacyanoferrate films," Journal of Electroanalytical Chemistry, vol. 547, no. 2, pp. 179-189, 2003.

[12] S. M. Chen and C. J. Liao, "Preparation and characterization of osmium hexacyanoferrate films and their electrocatalytic properties," Electrochimica Acta, vol. 50, no. 1, pp. 115-125, 2004.

[13] S. M. Chen, C. J. Liao, and V. S. Vasantha, "Preparation and electrocatalytic properties of osmium oxide/hexacyanoruthenate films modified electrodes for catecholamines and sulfur oxoanions," Journal of Electroanalytical Chemistry, vol. 589, no. 1, pp. 15-23, 2006.

[14] P. Kalimuthu and S. A. John, "Simultaneous determination of epinephrine, uric acid and xanthine in the presence of ascorbic acid using an ultrathin polymer film of 5-amino-1,3,4thiadiazole-2-thiol modified electrode," Analytica Chimica Acta, vol. 647, no. 1, pp. 97-103, 2009. 
[15] A. Salimi, C. E. Banks, and R. G. Compton, "Abrasive immobilization of carbon nanotubes on a basal plane pyrolytic graphite electrode: application to the detection of epinephrine," Analyst, vol. 129, no. 3, pp. 225-228, 2004.

[16] G. P. Jin, X. Peng, and Y. F. Ding, "The electrochemical modification of clenbuterol for biosensors of dopamine, norepinephrine, adrenalin, ascorbic acid and uric acid at paraffinimpregnated graphite electrode," Biosensors and Bioelectronics, vol. 24, no. 4, pp. 1031-1035, 2008.

[17] Y. Zeng, J. Yang, and K. Wu, "Electrochemistry and determination of epinephrine using a mesoporous $\mathrm{Al}$-incorporated $\mathrm{SiO}_{2}$ modified electrode," Electrochimica Acta, vol. 53, no. 14, pp. 4615-4620, 2008.

[18] X. Jiang and X. Lin, "Immobilization of DNA on carbon fiber microelectrodes by using overoxidized polypyrrole template for selective detection of dopamine and epinephrine in the presence of high concentrations of ascorbic acid and uric acid," Analyst, vol. 130, no. 3, pp. 391-396, 2005.

[19] Z. Yang, G. Hu, X. Chen, J. Zhao, and G. Zhao, "The nano-Au self-assembled glassy carbon electrode for selective determination of epinephrine in the presence of ascorbic acid," Colloids and Surfaces B, vol. 54, no. 2, pp. 230-235, 2007.

[20] B. Jin and H. Zhang, "Nano-gold modified glassy carbon electrode for selective determination of epinephrine in the presence of ascorbic acid," Analytical Letters, vol. 35, no. 12, pp. 1907-1918, 2002.

[21] T. Łuczak, "Electrocatalytic application of an overoxidized dopamine film prepared on a gold electrode surface to selective epinephrine sensing," Electroanalysis, vol. 20, no. 12, pp. 1317-1322, 2008.

[22] F. Ni, Y. Wang, D. Zhang, F. Gao, and M. Li, "Electrochemical oxidation of epinephrine and uric acid at a layered double hydroxide film modified glassy carbon electrode and its application," Electroanalysis, vol. 22, no. 10, pp. 1130-1135, 2010.

[23] F. C. Moraes, L. C. Golinelli, L. H. Mascaro, and S. A. S. MacHado, "Determination of epinephrine in urine using multi-walled carbon nanotube modified with cobalt phthalocyanine in a paraffin composite electrode," Sensors and Actuators B, vol. 148, no. 2, pp. 492-497, 2010.

[24] A. Ulman, "Formation and structure of self-assembled monolayers," Chemical Reviews, vol. 96, no. 4, pp. 1533-1554, 1996.

[25] Ž. Petrović, M. Metikoš-Huković, and R. Babić, "Potentialassisted assembly of 1-dodecanethiol on polycrystalline gold," Journal of Electroanalytical Chemistry, vol. 623, no. 1, pp. 5460, 2008.

[26] M. Adamovski, A. Zając, P. Grundler, and G. U. Flechsig, "Selfassembled monolayers on bismuth electrodes," Electrochemistry Communications, vol. 8, no. 6, pp. 932-936, 2006.

[27] S. F. Wang, D. Du, and Q. C. Zou, "Electrochemical behavior of epinephrine at L-cysteine self-assembled monolayers modified gold electrode," Talanta, vol. 57, no. 4, pp. 687-692, 2002.

[28] S. F. Liu, X. H. Li, Y. C. Li, Y. F. Li, J. R. Li, and L. Jiang, "The influence of gold nanoparticle modified electrode on the structure of mercaptopropionic acid self-assembly monolayer," Electrochimica Acta, vol. 51, no. 3, pp. 427-431, 2005.

[29] L. Wang, J. Bai, P. Huang, H. Wang, L. Zhang, and Y. Zhao, "Self-assembly of gold nanoparticles for the voltammetric sensing of epinephrine," Electrochemistry Communications, vol. 8, no. 6, pp. 1035-1040, 2006.

[30] W. Nowicki and G. Nowicka, "Verification of the SchulzeHardy rule," Journal of Chemical Education, vol. 71, no. 7, pp. 624-626, 1994.
[31] M. Bełtowska-Brzezinska, "Untersuchungen zum mechanismus der elektrochemischen oxidation von alkoholen an gold," Electrochimica Acta, vol. 25, no. 3, pp. 267-271, 1980.

[32] T. Łuczak, "Activity of gold towards methylamine electrooxidation," Journal of Applied Electrochemistry, vol. 37, pp. 461466, 2007.

[33] C. J. Zhong and M. D. Porter, "Evidence for carbon-sulfur bond cleavage in spontaneously adsorbed organosulfide-based monolayers at gold," Journal of the American Chemical Society, vol. 116, no. 25, pp. 11616-11617, 1994.

[34] H. A. Biebuyck, C. D. Bain, and G. M. Whitesides, "Comparison of organic monolayers on polycrystalline gold spontaneously assembled from solutions containing dialkyl disulfides or alkanethiols," Langmuir, vol. 10, no. 6, pp. 1825-1831, 1994.

[35] W. K. Paik, S. Eu, K. Lee, S. Chon, and M. Kim, "Electrochemical reactions in adsorption of organosulfur molecules on gold and silver: potential dependent adsorption," Langmuir, vol. 16, no. 26, pp. 10198-10205, 2000.

[36] S. Chon and W. K. Paik, "Adsorption of self-assembling sulfur compounds through electrochemical reactions: effects of potential, acid and oxidizing agents," Physical Chemistry Chemical Physics, vol. 3, no. 16, pp. 3405-3410, 2001.

[37] Q. Cheng and A. Brajter-Toth, "Selectivity and sensitivity of self-assembled thioctic acid electrodes," Physical Chemistry Chemical Physics, vol. 3, pp. 3405-3410, 2001.

[38] C. R. Raj, T. Okajima, and T. Ohsaka, "Gold nanoparticle arrays for the voltammetric sensing of dopamine," Journal of Electroanalytical Chemistry, vol. 543, no. 2, pp. 127-133, 2003.

[39] B. Ballarin, M. C. Cassani, E. Scavetta, and D. Tonelli, "Selfassembled gold nanoparticles modified ITO electrodes: the monolayer binder molecule effect," Electrochimica Acta, vol. 53, no. 27, pp. 8034-8044, 2008.

[40] A. Meier, I. Uhlendorf, and D. Meissner, "Electrochemical features of electrodes modified with Multiple Nano Contacts (MNCs) from colloidal noble metal particles," Electrochimica Acta, vol. 40, no. 10, pp. 1523-1535, 1995.

[41] H. Sellers, A. Ulman, Y. Shnidman, and J. E. Eilers, "Structure and binding of alkanethiolates on gold and silver surfaces: implications for self-assembled monolayers," Journal of the American Chemical Society, vol. 115, no. 21, pp. 9389-9401, 1993.

[42] Z. Jia, J. Liu, and Y. Shen, "Fabrication of a templatesynthesized gold nanorod-modified electrode for the detection of dopamine in the presence of ascorbic acid," Electrochemistry Communications, vol. 9, no. 12, pp. 2739-2743, 2007.

[43] J. Zhang and M. Oyama, "Electrocatalytic activity of threedimensional monolayer of 3-mercaptopropionic acid assembled on gold nanoparticle arrays," Electrochemistry Communications, vol. 9, no. 3, pp. 459-464, 2007.

[44] J. McMurry, Organic Chemistry, National Scientific, Warsaw, Poland, 2005.

[45] M. C. Leopold, J. A. Black, and E. F. Bowden, "Influence of gold topography on carboxylic acid terminated self-assembled monolayers," Langmuir, vol. 18, no. 4, pp. 978-980, 2002.

[46] E. Dempsey, A. Kennedy, N. Fay, and T. McCormac, "Investigations into heteropolyanions as electrocatalysts for the oxidation of adrenaline," Electroanalysis, vol. 15, no. 23-24, pp. 1835-1842, 2003.

[47] A. Kisza, Electrochemistry II, Technical Scientific, Warsaw, Poland, 2001.

[48] Analytical Methods Committee, The Analyst, vol. 112, pp. 199-204, 1987. 


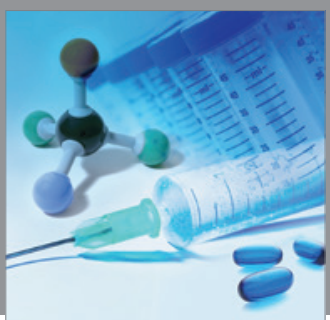

International Journal of

Medicinal Chemistry

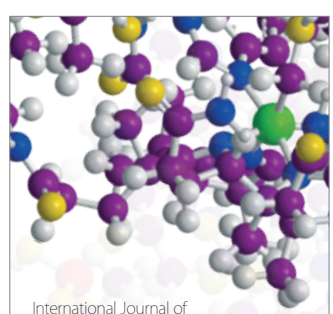

Carbohydrate Chemistry

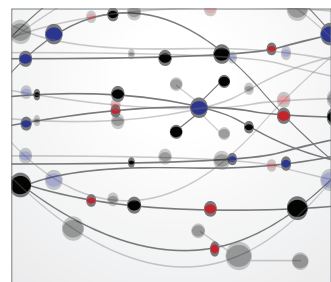

The Scientific World Journal
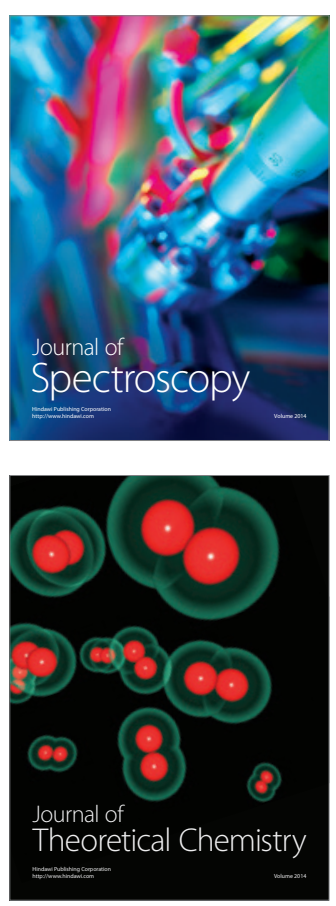


Submit your manuscripts at

http://www.hindawi.com
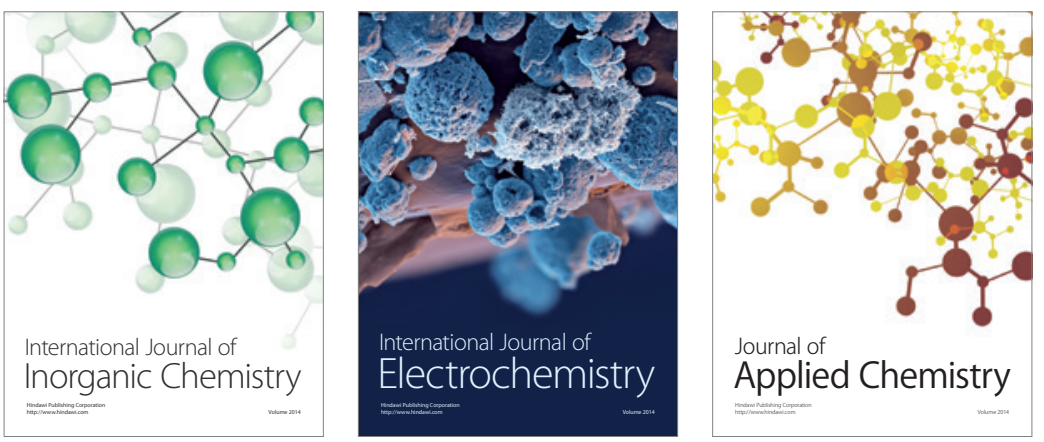

Journal of

Applied Chemistry
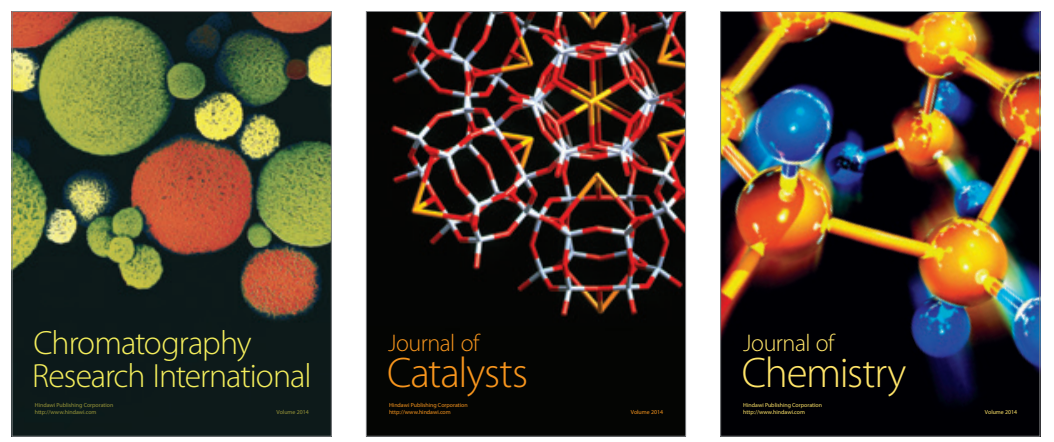
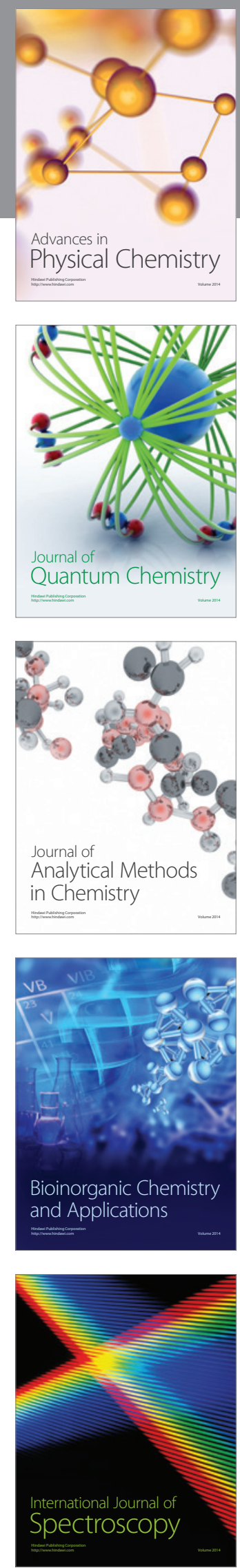